\title{
Comparative effects of a single treatment session using glucosamine sulphate and methyl salicylate on pain and hamstring flexibility of patients with knee osteoarthritis
}

\author{
Onigbinde Ayodele Teslim ${ }^{1}$, Adesina Olawale Daniel ${ }^{1}$, Tarimo Nesto ${ }^{2}$, Ojoawo Adesola ${ }^{1}$ \\ ${ }^{1}$ Department of Medical Rehabilitation, College of Health Sciences, Obafemi Awolowo University, Ile-Ife, Osun State, Nigeria \\ ${ }^{2}$ Physiotherapy department, Malawi Against Physical Disabilities, P. O. Box 256, Blantyre, Malawi
}

\section{Email address:}

ayotesonigbinde@yahoo.co.uk (A. T. Onigbinde)

\section{To cite this article:}

Onigbinde Ayodele Teslim, Adesina Olawale Daniel, Tarimo Nesto, Ojoawo Adesola. Comparative Effects of a Single Treatment Session Using Glucosamine Sulphate and Methyl Salicylate on Pain and Hamstring Flexibility of Patients with Knee Osteoarthritis. American Journal of Health Research. Special Issue: Supplementary Prescribing in Nigeria: A Needy Concept to Promote Clinical Physiotherapy Practice. Vol. 2, No. 5-1, 2014, pp. 40-44. doi: 10.11648/j.ajhr.s.2014020501.18

\begin{abstract}
Transdermal delivery of topical medications is commonly used for managing osteoarthritis (OA). Osteoarthritis of the knee joint impairs lower limb functions which contributes to poor gait patterns. There is insufficient empirical data to support the efficacy of glucosamine sulphate and methyl salicilate cream in the management of knee OA. The aims of this study were to compare the immediate effects of glucosamine sulphate and methyl salicylate cream on pain, flexibility and knee flexion. Forty one subjects with grade 11 knee OA were recruited for the study. They were randomly assigned to 2 groups. One gram of each topical formulation was administered to the knee joint using massage. Pre and post-intervention pain intensities, hamstring flexibilities and active knee flexion were measured. Descriptive, paired and independent t-tests statistics were used to analyze the data. There were significant reduction in pain intensities within the groups $(t=9.08, p<0.001 ; t=6.29, p<0.001)$. However, there was no significant difference in the post treatments pain intensities across the two groups. There were significant increase in the flexibilities of groups 1 and 2 post treatment $(t=9.14, p<0.001)$ and $(t=-5.67, p<0.001)$ respectively but there was insignificant difference in the flexibilities of the groups. Similarly, there was insignificant difference in the range of motion when the active knee flexions of the two groups were compared. We concluded that transdermal massage of glucosamine was as effective as methyl salicilate in alleviating pains, improving hamstring flexibility and increasing knee flexion range of motion in a single treatment session among knee OA participants in this study.
\end{abstract}

Keywords: Glucosamine Sulphate, Methyl Salicilate, Pain, Hamstring Flexibility, Knee Osteoarthritis

\section{Introduction}

Osteoarthritis refers to a syndrome of joint pain accompanied by functional limitation and reduced quality of life [1]: In a Nigeria rural community, prevalence of knee Osteoarthritis (OA) was $21.4 \%$ for female and $17.5 \%$ among male, and one out of every five adults of aged greater or equal to forty years have symptoms of OA [2]. Men are mostly affected by OA before age 55, while women are mostly affected after age 55 [3]. Aging has also been observed to increase the risks of developing OA [4]]. Osteoarthritis is characterized by loss of articular cartilage, bone remodeling, structural atrophy which subsequently results to chronic pain, stiffness, and limited activities of daily living [5,6]. Osteoarthritis at the knee is the most common cause of chronic disability among the elderly worldwide [7]. Aside pain, loss of muscle power and decreased range of motion, there is also loss of hamstring flexibility [8].

Flexibility is the ability to move a single joint or series of joints smoothly and easily through an unrestricted pain free range of motion [9]. Flexibility is related to the extensibility of musculo-tendinous units that cross a joint, based on the ability to relax, deform and yield to a stretch force. There are two types of flexibility namely; dynamic and passive flexibility [10]. Flexibility training is an integral component in conditioning programs for sporting activities [11]. The flexibility of the quadriceps and hamstring groups of muscles determines the smoothness and precision of ambulatory 
pattern while inadequate flexibility predisposes individuals to injury and musculoskeletal dysfunctions [12].

Topical Non-steroidal Anti-Inflammatory Drugs (NSAIDs) are usually drugs of choice for localized symptoms of osteoarthritis especially for individual at risk of adverse reactions [6]. Topical analgesics and NSAIDs by-pass gastrointestinal system, and this prevent adverse reactions associated with oral administration [13]. Recently, researchers have focused attention on the use of glucosamine in management of osteoarthritis [14]. However, methyl salicilate appears to be drugs of choice among Nigerians physiotherapists probably due to cost of glucosamine. Methyl salicylate has been proven to be efficacious in the management of knee osteoarthritis; it enhances pain relief and increases functional activities [15]. Glucosamine is used as the starting material for tendon, ligament and synovial fluid of the joint [14].

Transdermal drug delivery has been used widely in clinical practice but it is yet to fully achieve its potential as an alternative to oral delivery and hypodermic injections [16]. Currently, there are 19 transdermal delivery systems and these include iontophoresis, ultrasonophoresis and massage $[16,17]$. The use of massage is an age -old process that involves stimulations of the tissues by rhythmically applying both stretching and pressure [18]. The study of the penetration of drug through the skin has become increasingly important in the recent years but there are still challenges on how to maximize the bioavailability of drugs to enhance the therapeutic efficacy with minimal side effects [13].

There are several challenges facing the management of osteoarthritis. The treatments are always focused on pains, restricted joint motions and decreased muscle strength, neglecting ligamentous and muscular tightening (flexibility) which affects lower limb functions and gait [19]. Onigbinde et al and Ozcan et al reported that hamstring tightness significantly correlated with knee osteoarthritis [19, 20]. Hence, there is need to focus attention on its effective management. Oral glucosamine has been suggested to improve flexibility; likewise, glucosamine iontophoresis has also been reported to be efficacious in managing osteoarthritis [8]. Also methyl salicylate iontophoresis has been proven to enhance pain relief and functional activities [15]. Non -availability and expensiveness of galvanic stimulators, and lack of knowledge about iontophoresis; appears to be restricting the application of iontophoresis [21]. In view of this, there is need to emphasize the use of costeffective techniques such as transdermal massage, if established to be effective. The application of both glucosamine and methyl salicilate are common in the management of OA in most clinics but there is still dearth of empirical data on which is more effective in alleviating pain and increasing hamstring flexibility.

The aims of this study were to compare the immediate effects of transdermal massage of both glucosamine sulphate and methyl salicylate on pain, hamstring flexibility and knee flexion range of motion. It was hypothesized that there would be no significant differences in the effects of glucosamine sulphate and methyl salicylate on pain intensity, hamstring flexibility and knee flexion range of motion using transdermal massage.

\section{Materials and Method}

\subsection{Participants}

Forty one subjects with knee OA, who were receiving treatment at the outpatient orthopeadic unit of two selected work settings, were participants in the study.

\subsection{Study Settings}

Research was conducted at the physiotherapy department, ObafemiAwolowo University Teaching Hospital Complex (OAUTHC), Ile-Ife and Ladoke Akintola University Teaching Hospital, Osogbo, both in Osun State, Nigeria.

\subsection{Sampling Technique}

Purposive sampling technique was used to select participants with knee OA among 96 patients with knee pathologies. They were randomly assigned into 2 groups using balloting. Figure 1 and 2 were written on two ballot papers and covered in a ballot bowl, each participant was instructed to pick a ballot; whatever, ballot picked was the group that the participants were assigned to. The sample size required for this study was computed to be 60 but only 41 met the inclusion criteria at the time of this study.

\subsection{Inclusion and Exclusion Criteria}

The two major inclusive criteria were radiological evidence of grade 11 knee OA and the onset of duration must be greater than three months. Participants with fever, tumors, cardiovascular and neurologic disorders; and other knee pathologies asides OA were excluded from the study.

\subsection{Research Design}

The design was a pre-test and post-test (quasi) experimental design.

\subsection{Instrumentations}

The modified sit and reach flexibility box was used to measure the hamstring flexibility. A short armed half circle plastic goniometer was used to measure the active knee flexion while stadiometer was used to measure the height of the participants. The visual analogue scale was used to evaluate pain intensity and bathroom weighing scale was used to measure the weight $(\mathrm{Kg})$ of the participants.

\subsection{Procedure}

Ethical approval was obtained from the ethical review committee of the Institute of public health (IPH/OAU/12/161), Obafemi Awolowo University Ile-Ife, Osun state, Nigeria. The consent of the subjects was also obtained, and the experimental procedure was explained and 
demonstrated to each participant. The group 1 participants had transdermal massage of 2 Finger Tip Units (FTU), equivalence of $1 \mathrm{~g}$ glucosamine sulphate (Urah) while the second group had the same dose but of methyl salicylate (Neurogesic). The deep stroking massage technique was used to apply the creams to the knee joint. Both group had a baseline interventions in the form of infra-red radiation therapy and bicycle ergometry for 15 minutes each.

Prior to the study, the weight and height were measured for both groups using standardized procedure. The VAS (10 point scale) was explained to all participants. The VAS had been found to be effective in assessing pain arising from knee osteoarthritis [22]. Participants were asked to rate pain experienced at the knee joint during full active knee flexion range of motion.

The modified sit and reach test was used to determine the flexibility of the participants in both groups. The subjects sat on a mat with the hip at 90 degree and the two arms outstretched. The flexibility box was placed at the distal end of the feet of the lower limbs (with shoes removed) touching the sole of the feet with an adjustable $(100 \mathrm{~cm})$ meter ruler fixed at the center of the box and in between the 2 big toes with the zero meters at the tip of the right middle finger. The subjects were asked to flex the spine and slide their fingers along the table as far as possible to a new position. The point of the tip of the middle finger on the ruler was noted and was taken as the flexibility [13]. Pain intensity, hamstring flexibility and knee flexion range of motion for the two groups were measured pre and post interventions in a single treatment session.

\subsection{Data Analysis}

Both descriptive and Inferential (paired and independent ttests) statistics were used to analyze the data. The level of significance was set as 0.05 levels.

\section{Result}

\subsection{Comparison of the Physical Characteristics of the Two Groups}

Table 1. Physical characteristics of participants

\begin{tabular}{lllll}
\hline Variables & $\begin{array}{l}\text { Group 1 } \\
\text { Mean (SD) }\end{array}$ & $\begin{array}{l}\text { Group 2 } \\
\text { Mean (SD) }\end{array}$ & t & p \\
\hline Age & $66.86(8.94)$ & $64.20(9.41)$ & 0.93 & 0.36 \\
Weight & $71.90(12.55)$ & $73.60(10.61)$ & -0.48 & 0.64 \\
Height & $1.67(0.58)$ & $1.63(0.78)$ & 2.29 & 0.03 \\
BMI & $27.96(5.26)$ & $25.73(3.93)$ & 1.54 & 1.31 \\
\hline
\end{tabular}

There were $9(42.9 \%)$ and 12 female $(57.1 \%)$ in the glucosamine group while there were $2(10 \%)$ male and 18 $(90 \%)$ female in the methyl salicylate group. The mean age of participants in the glucosamine group (group I) was 66.86 \pm 9.41 years and that of methyl salicylate group (group 2) was $64.20 \pm 8.94$ years. The weight, height and BMI of the two groups are presented in table 1.The result of the independent t-test showed that there was no significant difference in age, weight and BMI of the two groups. However, there was significant difference in the height of the two groups $(t=2.30$, $\mathrm{p}=0.03)$.

\subsection{Comparison of the Pain Intensities, Flexibilities and Active Knee Flexion of the Two Groups}

On a 10-point pain rating scale, the mean initial pain intensity score of the glucosamine (group 1) participants was $6.67 \pm 1.11$ while post treatment it was $4.19 \pm 1.44$ on a 10 point pain rating scale. The initial and post intervention pain intensities of methyl salicylate group (group 2) are also presented in table 2 . There were significant reduction in pain intensities of groups 1 and 2 post treatment $(t=9.08$, $\mathrm{p}<0.001)$ and $(\mathrm{t}=6.29, \mathrm{p}<0.001)$ respectively. However, there was no significant difference in the post treatments pain intensities across the two groups (Tables 2).

The initial flexibility score of glucosamine (group1) participants was $21.71 \pm 7.76 \mathrm{~cm}$ while post treatment it was $26.95 \pm 8.34 \mathrm{~cm}$. The initial and final flexibility scores of methyl salicylate (group 2) participants are presented in table 2. There were significant increase in the flexibilities of groups 1 and 2 post treatment $(\mathrm{t}=9.14, \mathrm{p}<0.001)$ and $(\mathrm{t}=-$ $5.67, \mathrm{p}<0.001)$ respectively. The result of independent $\mathrm{t}$-test showed that there was no significant difference in flexibility of the two groups. The active knee flexion ranges of motions are presented in table 2. Similarly, there were significant differences in the pre and post interventions values for active knee flexion range of motions in the two groups $(\mathrm{t}=1.44$, $\mathrm{p}<0.001)$ and $(\mathrm{t}=0.76, \mathrm{p}<0.001)$. However, there was no significant difference in active knee flexion ROM of the two groups (Table 2).

\section{Discussion}

In knee OA, tight muscle increases the compression of the joint while tightening of quadriceps, hamstring and calf muscle results in poor coordination and slower reaction time [23]. Transdermal topical analgesics and NSAIDs are few of the numerous drugs being used in managing OA. Transdermal drug delivery is limited to very few drugs that have low molecular weights and high to moderate lipophilicity $[16,24]$. Topical delivery permits the avoidance of first pass metabolism by the liver and the delivery of a more even level of the therapeutic agent over the course of 24 hours and it also bypasses the gastric system providing higher levels and quicker tissue saturation [17, 24]. It is generally accepted that transdermal delivery improves patient compliance [24].

The American Academy of Orthopaedic Surgeons (AAOS) suggested using non-pharmacologic means to alleviate pain being experienced from $\mathrm{OA}$ and also strengthen muscle with low intensity exercises [6].being experienced from OA. There are different types of topical formulations such as Motion Medicine (MM) and Professional Therapy Muscle Care Products $[25,26,27]$. They contain anti-inflammatory compounds (methyl salicylate and methylsulfonylmethane) and ingredients that may facilitate tissue repair (glucosamine, condroitin, vitamin E, grape seed and sea cucumber extract 
[25].

It was observed that the administration of 1 gram each of both glucosamine sulphate and methyl salicylate cream were effective in alleviating pain experienced by knee OA subjects in this study. The reduction in pain intensity was similar to the reduction observed when glucosamine sulphate was administered by iontophoresis in subjects with sub-acute knee osteoarthritis [13]. However, we found no superiority in the ability of both topical medications to alleviate pains. Topical glucosamine had been reported severally to be safe and effective in relieving the pain associated with knee osteoarthritis [27]. However, controversy still trails the relative efficacy of glucosamine, in its ability to truly modify the progression of OA $[28,29]$. However, evidences have shown that glucosamine improve joint structures [30]. The previous guidelines of the American Pain Society and American College of Rheumatology recommended topical methyl salicylate for effective management of OA but recent reports doubts its significant efficacy [31].

Although, we observed that post intervention, methyl salicilate was able to significantly reduce the pains experienced by participants in the group. Methyl salicylate is a counterirritant used to enhance pain relief and functional activities [15]. It is a non-steroidal anti-inflammatory drug used to reduce inflammation and as an analgesic to reduce pain especially in osteoarthritis and like other NSAIDs it acts by inhibiting the mediators of the inflammatory response to injury such as prostaglandins [32]. There was also insignificant difference in the hamstring flexibility when the post intervention values of both glucosamine and methyl salicilate groups were compared. However, the post treatment flexibility values within the groups were significantly higher than the pre treatment values. A similar trend was observed when Onigbinde et al used electromotive force (iontophoresis) to administer glucosamine sulphate [8]. They found significant acute effect of glucosamine iontophoresis in improving hamstring flexibility of knee OA patients. There was also no significant difference in the post treatment knee flexion range of motion of both groups, implying that they have the same effect on improving range of motion. Within each group, there were improvements in knee flexion range of motions.

Table 2. Comparison of pain intensities, flexibility and knee flexion range of motions of participants across the groups

\begin{tabular}{llllll}
\hline Interventions & Variables & Glucosamine Mean \pm SD & Methyl Salicylate Mean \pm SD & t & p \\
\hline \multirow{3}{*}{ Pre } & Pain intensity & $6.67 \pm 1.11$ & $6.31 \pm 1.08$ & -1.04 & 0.30 \\
& Flexibility & $21.71 \pm 7.76$ & $21.8 \pm 6.64$ & 0.04 & 0.97 \\
& Knee flexion & $67.14 \pm 6.99$ & $70.30 \pm 7.06$ & 1.44 & 0.16 \\
\multirow{3}{*}{ Post } & Pain intensity & $4.19 \pm 1.44$ & $4.90 \pm 0.91$ & 1.88 & 0.07 \\
& Flexibility & $26.95 \pm 8.34$ & $25.4 \pm 5.91$ & -7.71 & 0.48 \\
\hline
\end{tabular}

The efficacy of methyl salicilate corroborated that of Wani et al who also reported methyl salicilate increased functional activities among subjects with knee OA [15]. Also, recent studies have indicated that glucosamine sulfate possesses antioxidant properties, thereby, suppressing high concentrations of reactive oxygen species (ROS) which cause the breakdown of cartilage due to the presence of free radicals and pro-oxidants [33]. Also, in an animal study, range of joint motion increased significantly at the elbow joint with an increase in selected gait parameters following oral administration of glucosamine sulphate [34]. Previous reports had also established that drugs are detectable underneath site of application using transdermal administration techniques [35]. The effect of massage includes improving cutaneous blood circulation closer to the surface of the skin allowing faster absorption of drugs [17]. The massage technique would have also enhanced the absorption of glucosamine and methyl salicilate cream to facilitate the improvement we observed in this study.

\section{Conclusion}

We concluded that transdermal massage of glucosamine was as effective as methyl salicilate in alleviating pain experienced by knee OA participants in this study. Also, they are equally effective in improving hamstring flexibility and increasing knee flexion range of motion in a single treatment session.

\section{References}

[1] Conaghan Philip G, John Dickson, Robert L Grant, Care and management of osteoarthritis in adults: summary of NICE guidance. BMJ. Mar 1, 2008; 336 (7642): 502-503.

[2] Akinpelu AO, Alonge TO, Adekanla BA, Odoles AC. Prevalence and Pattern of Symptomatic Knee Osteoarthritis in Nigeria: A Community-Based Study. The Internet Journal of Allied Health Sciences and Practice. July 2009, Volume 7 Number 3, $1-7$.

[3] Arthritis Foundation. Osteoarthritis. http://www. arthritis.org/conditions/diseasecenter/oa.asp. Accessed on 14th August, 2002.

[4] Barkin RL, Beckerman M, Blum SL, Clark FM, Koh EK, Wu DS. Should nonsteroidal anti-inflammatory drugs (NSAIDs) be prescribed to the older adult? Drugs Aging. 2010; 27(10):775-789.

[5] Felson DT. Developments in the clinical understanding of osteoarthritis. Arthritis Res Ther. 2009; 11 (1):203.

[6] Stanos Steven P. Osteoarthritis guidelines: a progressive role for topical nonsteroidal anti-inflammatory drugs. Journal of Multidisciplinary Healthcare, 2013, 6, 133-137. 
[7] Guccione AA, Felson DT, Anderson JJ, et al. The effects of specific medical conditions on the functional limitations of elders in the Framingham Study. Am J Public Health.1994; 84 (3):351-8. [PMC free article] [PubMed]

[8] Onigbinde A. T, Talabi A.E, Ojoawo A.O, Adedoyin R.A, Onifade O.A, Olaitan O.L, Oniyangi S, Belloni O. Effects of glucosamine sulphate iontophoresis on hamstring flexibility of subjects with knee osteoarthritis Medicinal Sportiva- Journal of Romanian Sports Medicine, 2010, vol iv, 2, 1405 - 1410.

[9] Halbertsma JP, Van Bolhuis Al, Goeken LN. Sport stretching: effect on passive muscle stiffness of short hamstrings. Arch Phys Med Rehabil; 1996, 77:688-692.

[10] Kisner Carolyn, Colby Lynn Allen. Stretching for impaired mobility, definitions of terms related to mobility and stretching, flexibility. Therapeutic Exercise: Foundations and Techniques, $5^{\text {th }}$ edition, 2007 .

[11] Russel T, Nelson and Williams D. Bandy. Eccentric training and static stretching to improve hamstring flexibility of High School males; Journal of Athletic Training, 2004, 39(3):254-258.

[12] Newell Lori. Hamstring Exercises for Osteoarthritis.Livestrong.com. http://www.livestrong. com/article/529606- hamstring-exercises-for-osteoarthritis, 2011. Accessed on 22nd April 2013

[13] Onigbinde A T, Talabi A E, Okulaja I.A, Dominic O. Comparative efficacy of cycle-ergometry exercise and glucosamine sulphate iontophoresis in pain management of subjects with sub-acute knee osteoarthritis. Medicinal Sportiva, 2011, Vol vii, No 1517-1521.

[14] The Glucosamine osteoarthritis resource centre (2005): Glucosamine and Osteoarthritis;http://www.glucosamineosteoarthritis.org/glucosamine/Glucosamine -for-arthritis.html. Accessed on 22nd April 2013.

[15] Wani S.K and Gaikwad P. Comparative efficacy of methyl salicylate iontophoresis and moist heat pack in the management of knee osteoarthritis. International Journ. Of Therapy and Rehabilitation, 2012, 19, 10, $541-548$.

[16] Prausnitz Mark R and Langer Robert (2008).Transdermal drug delivery. Nat Biotechnol. Nov 2008; 26(11): 1261-1268.

[17] Comiskey Bill. Elements Transdermal Massage: Relaxes the body, calms the mind. http://www.massagewarehouse.com/assets/item/ document/ Elements- Transdermal-Massage. Accessed on 3rd July 2014.

[18] Watt Joan. Massage for sports. ISBN-10: 1861261608, $1^{\text {st }}$ Edition, Crowood Press, Limited 2014.

[19] Onigbinde Ayodele Teslim, Oluukola Akindoyin, Funmilola Adenike Faremi, Adaobi Okonji, Oniyangi Shuaib, Olaitan Olukunmi Lanre. An assessment of hamstring flexibility of subjects with knee osteoarthritis and their age matched control. Clinical Medicine Research, 2013, 2 (6): 121-125.

[20] Ozcan O, Boya H, Haluk H O. Clinical evaluation of the proximal tibiofibular joint in knees with severe tibiofemoral primary osteoarthritis. Knee, 2009, 16 [4]: 248-50.

[21] Onigbinde Ayodele Teslim, Orolade Ibidayo Akanji. An assessment of knowledge and opinion of Nigerian physiotherapists on application of Iontophoresis in the management of selected skin disorders and Arthritis. Technology and Health Care, 2012, 20, 169-177.
[22] Adedoyin R.A, Olaogun M.O.B, Fagbeja O.O. Effect of interferential current stimulation in the management of osteoarthritis pain, Physiotherapy, 2002, 88(8):493-499.

[23] Coreconcepts Musculosletetal Health Group. http//:www.coreconcepts. com.sg/mcr/ osteoarthritis-knee/ retrieved $13^{\text {th }}$ April 2013

[24] APBN. Transdermal drug delivery, 2007, Vol. 1, No 6, 336 $399 . \quad \mathrm{http}: / / \mathrm{www}$. asiabiotech.com /publication/apbn/11/english/preserved-docs. Accessed on 3rd July 2014.

[25] Fox Colleen and Koren Gideon The Motherisk Program. Hospital for Sick Children and the University of Toronto. http://www.musclecare.net/wpcontent/themes/musclecare/img/01_PTMC_Toxicology_Revie w Abstract And Refs.pdf. Accessed on 3rd July 2014.

[26] Oswald Chris. Professional therapy muscle care pain relieving ointment. http://dailymed.nlm.nih.gov/dailymed/lookup.cfm. Accessed on 3rd July 2014.

[27] Johnson Dustin L. Safety and Efficacy Data of the Constituent Ingredients of Motion Medicine, Healthy Environments and Consumer Safety Branch, Health Canada. www.safetyefficacy/data-of-the-constituentingredients/motionmedicine. Accessed on the 2nd July 2014.

[28] Cohen, M., R. Wolfe, T. Mai, and D. Lewis. A randomized, double blind, placebo controlled trial of a topical cream containing glucosamine sulfate, chondroitin sulfate, and camphor for osteoarthritis of the knee. J. Rheumatol. 2003, 30:523-528.

[29] Reginister J, Bruyere O, Lecart M, Henroitin Y. Naturocetic (glucosamine and chondroitin sulfate) compounds as structure-modifying drugs in the treatment of Osteoarthritis Current Opinion in Rheumatology 2003; 15 (5):651-5. CrossRef, PubMed.

[30] Braham R, B Dawson, C Goodman.The effect of glucosamine supplementation on people experiencing regular knee pain. British Journal of Sports Medicine; 2003, 37:45.

[31] Altman R, Barkin RL. Topical therapy for osteoarthritis: clinical and pharmacologic perspectives. Postgrad Med. 2009, Mar;121 (2):139-47

[32] Towheed TE, Maxwell L, Judd MG, Catton M, Hochberg MC, Wells G. "Acetaminophen for osteoarthritis". Cochrane Database Syst Rev (1): CD004257. doi:10.1002/ 14651858. CD004257.pub2. PMID 1643747,2006. Accessed on the 2nd July 2014.

[33] Illy Gena de and Duberstein Kylee. Effects of daily oral supplementation of glucosamine sulfate on joint range of motion and serum oxidative stress in aged performance horses. http://www.ads.uga.edu/documents/EffectsofDaily OralSupple -mentationof Glucosamine. pdf. Accessed on 3rd July 2014.

[34] Forsyth RK, Brigden CV, Northrop AJ. Double blind investigation of the effects of oral supplementation of combined glucosamine hydrochloride (GHCL) and chondroitin sulphate (CS) on stride characteristics of veteran horses. Equine Vet J Suppl. 2006, Aug, (36):622-5.

[35] Onigbinde A.T. Adedoyin R.A., Johnson O.E. Effect of Physical Therapy Intervention on Pharmacokinetic Variables. Nigerian Journal of Medical Rehabilitation, 2006, Vol, 11, No 19, June, 1 - 5 . 